\title{
A Decision-Support System for the Car Pooling Problem
}

\author{
Riccardo Manzini, Arrigo Pareschi \\ Department of Industrial Engineering, Bologna University, Bologna, Italy \\ Email: riccardo.manzini@unibo.it
}

Received January 29, 2012; revised March 1, 2012; accepted March 16, 2012

\begin{abstract}
The continuous increase of human mobility combined with a relevant use of private vehicles contributes to increase the ill effects of vehicle externalities on the environment, e.g. high levels of air pollution, toxic emissions, noise pollution, and on the quality of life, e.g. parking problem, traffic congestion, and increase in the number of crashes and accidents. Transport demand management plays a very critical role in achieving greenhouse gas emission reduction targets. This study demonstrates that car pooling (CP) is an effective strategy to reduce transport volumes, transportation costs and related hill externalities in agreement with EU programs of emissions reduction targets. This paper presents an original approach to solve the CP problem. It is based on hierarchical clustering models, which have been adopted by an original decision support system (DSS). The DSS helps mobility managers to generate the pools and to design feasible paths for shared vehicles. A significant case studies and obtained results by the application of the proposed models are illustrated. They demonstrate the effectiveness of the approach and the supporting decisions tool.
\end{abstract}

Keywords: Car Pooling; Clustering Analysis (CA); Passenger Transportation Modes; Vehicle Efficiency; Sustainability Transport; Transport Demand Management

\section{Introduction}

In last decade, international environment agencies, e.g. the European Environment Agency (EEA), are searching for effective challenges to reduce the environmental impacts of transport and to improve the environmental performance of the transport system as a whole. In particular, several studies and reports demonstrate that current developments in the transport sector are not compatible with the need to reduce harmful air pollutant emissions (e.g. $\mathrm{NO}_{x}, \mathrm{SO}_{2}$, particulates, $\mathrm{PM}_{10}$ ) and overall greenhouse gas emissions responsible of climate change. Technology can deliver some of the reductions needed, but needs to be significantly supported by behavioural changes. This is true especially in countries such as Italy, where the passenger transport demand by private cars was $79.1 \%$ in 2004 [1]. Even if between 2007 and 2008 passenger transport demand in the EEA-32 declined, most likely due to the impacts of the global economic recession, overall passenger transport demand has grown by over a fifth since 1995 . Italy counts a very high percentage (about $30 \%$ ) of the EEA members' fleet of motorbikes and mopeds, and does not yet widely adopt transportation modes, e.g. vehicle sharing, able to reduce vehicle usage and ownership if compared to countries such as UK or Switzerland.

This paper deals with the car-pooling problem (CPP). Car pooling $(\mathrm{CP})$ can be categorized into two different forms: Daily Car Pooling Problem (DCPP) and Longterm Car Pooling Problem (LTCPP). For DCPP, on each day a number of users are available for picking up or bringing back their colleagues in that particular day [2]. For LTCPP, each user has to act as both a server and a client; the objective is to define user pools where each user will pick up the remaining pool members in turn, on different days. The aim is the minimization of the amount of used vehicles and the total distance travelled by all users when acting as servers, subject to car capacity and time window constraints. The problem discussed in this paper deals with LTCPP.

$\mathrm{CP}$ is an effective strategy to guarantee and support sustainable transport and sustainable mobility. It is "the ability to meet the needs of society to move freely, gain access, communicate, trade, and establish relationships without sacrificing other essential human or ecological values today or in the future" (World Business Council for Sustainable Development [3]).

$\mathrm{CP}$ is a special typology of the basic strategy of sharing vehicles to directly reduce the use of private cars, the requirement of parking space, and indirectly contribute to reduce vehicle externalities including emissions of greenhouse, crash costs, roadway congestion, space consumption, etc. CP is a service organized by companies that encourage their employees to travel to/from a specific location, e.g. the work location, in groups. The generic group of employees, called pool or cluster, shares 
vehicles and paths in order to minimize the global cost of the system, as the sum of vehicles fixed costs and variable travelling costs.

Other significant strategies and solutions, the so-called sustainable passenger transportation modes, to manage mobility and traffic due to people and workers moving are: car/van/bike sharing, ride-sharing, lift-sharing, public vehicles (e.g. buses, electric cars, metro), hybrid cars, bikebus and walkbus for students going to school, personal automated transport (PAT) or podcar, tool roads for which a driver pays a fee for use, restricted urban entry zones, high-occupancy vehicle (HOV) lanes. In particular, the HOV lanes are also known as carpool lanes, commuter lanes, diamond lanes, express lanes, and transit lanes, and regularly carry more people than adjacent regular lanes of travel.

Unfortunately, CP is not yet a solution adopted by many companies and institutions as the car sharing is. In Italy there are a very high number of cars for each family and person (690 vehicles per 1000 people) because many Italian families are used to be owner of at least one car and prefer to go to the location of work by themselves using one of their own vehicles [4]. A wide diffusion of $\mathrm{CP}$ by the large number of medium-large companies would significantly contribute to reduce the ill effects of an unconditional and selfish use of private vehicles.

Literatures presents a few contributions on models and tools, i.e. rules, procedures and issues, usable by mobility managers to best define and organize poolers matching and vehicle routing. They are very complex and not directly comprehensible to mobility managers $[5,6]$. Moreover, discussions on significant case studies are not frequently presented.

To further support the diffusion of $\mathrm{CP}$, this paper presents the development of an effective approach to solve the CPP, and an original DSS to help mobility manager to daily generate pools of users and identify the best routing of vehicles. This paper also presents a what-if multi-scenario analysis conducted on a significant case study.

The rest of the paper is organized as follows: Section 2 presents the literature review on CPP and a set of significant statistics encouraging and justifying the adoption of effective strategies and tools to reduce gas emissions and externalities. Section 3 presents the proposed hierarchical approach to the clustering analysis, the formation of groups and the routing of vehicles within each obtained cluster. Section 4 illustrates the DSS developed for the automation of the proposed models and procedures. Section 5 presents the results of the group formation and vehicle routing process by the application of the proposed cluster-first route-second approach to a case study of about 1900 potential participants to a CP program. Finally, Section 6 presents conclusion and further re- search.

\section{Literature Review}

Literature presents several studies monitoring the environmental performance of different transportation modes in different countries and in accordance to the growing of transportation demand. The authors, as citizens of EU member States, reports statistics, analyses, strategies and policies, and targets which refers to the European transportation system and issues.

In particular, the European Environmental Agency (EEA) and the Environmental Reporting Mechanism (EEA TERM) introduce a framework to integrate indicators useful to monitor both transport and environment issues and identifying rules and tools to improve the performance of a transport system.

The analysis, control and optimization of transportation modes and usage in accordance with climate change and environmental issues, are based on several focuses: focus on road transport, rail transport, air transport, waterborne transport, non motorised transport (e.g. cycling and walking), land use and planning, etc. [7] presents an interesting investigation on what car-use reduction measures are perceived by households to be feasible to reduce car driving.

The study proposed in this paper deals with road transport, whose main two topics are:

1) Transport for the trading sectors and moving of materials, known as freight transport, i.e. logistics \& distribution;

2) Transport for non trading sectors and moving of passengers.

Literature presents several studies on the minimization of travelling costs and indirectly gas emissions and externalities in logistics and distribution. A few significant examples are proposed by [8] and [9] presenting original models and tools for the design, management and control of a freight transportation system. They also present a survey on literature studies on supply chain management and distribution network optimization with particular attention to the minimization of distances travelled by vehicles in presence of different transportation modes (road, rail, air). Several studies deal with sustainable transport and mobility of passengers but a few of them present effective tools usable by mobility managers to implement planning decisions regarding commuting. Commuting is the basic philosophy of car sharing and CP issues and rules. [10] presents heuristic algorithms based on saving functions for the CPP. The computational complexity of the CPP is NP-hard.

A set of significant statistics on the attitudes of EU members towards different passenger transportation modes, the related effects and the environmental exter- 
nalities, follow [11-13].

- $\mathrm{CO}_{2}$ emissions. During 1990-2004 the emissions of $\mathrm{CO}_{2}$ increased by $27 \%, 26.079$ million tonnes (Mt $\mathrm{CO}_{2}$ ) in 2004, while the energy demand from the transport sector increased by $37 \%$. In particular, USA and China respectively increased by $19 \%$ and $108 \%$ in term of $\mathrm{CO}_{2}$ emissions, and by $28 \%$ and $168 \%$ in term of energy demand.

- For the 27 EU Member States (EU-27) the greenhouse gas emission 2020 projections are $1091 \mathrm{Mt}$ $\mathrm{CO}_{2}$ - eq. (767 Mt $\mathrm{CO}_{2}$ - eq. reported in 1990), assuming a $15 \%$ growth in transport volume between 2010 and 2020 and no further reduction measures, and excluding air and maritime transport.

- Passenger car use. It grew by $18 \%$ between 1995 and 2004 , and it was responsible for $74 \%$ of all passenger transport in 2004. In 2005 the average car ownership level is 777 in the USA per 1000 inhabitants, while it is 460 in the 32 EEA members, including $27 \mathrm{EU}$ states, Turkey, Norway, Iceland, Liechtenstein and Switzerland. The increase of car ownership rates reduces the average number of passenger per car and does not contribute to cut greenhouse gas emissions. High levels of ownership rate do not improve vehicle efficiency.

- In 2003 the road network, including motorways, represented about $95 \%$ of the total, including also railway lines, oil pipelines and inland waterways. In particular, Italy presents the following key indicators related to railways in 2003: $28 \mathrm{~km}$ per 100,000 inhabitants and $54 \mathrm{~km}$ per 1000 squared $\mathrm{km}$.

- Responding to a questionnaire, only $22 \%$ of EU citizens stated that they would not consider reducing car usage under any circumstances [14].

- In UK there was a total membership of car sharing clubs of 23,000 in 2006 [15].

Strategies and policies to ensure better capacity utilisation within each transportation mode may result in substantial additional reductions of $\mathrm{CO}_{2}$ emissions and other externalities [11]. Moreover, the increase of transport demand and car usage, and the reduction of the number of passengers per car negate the improvements gained from the improvements in vehicle efficiency, such as 120 $\mathrm{g} \mathrm{CO}_{2} / \mathrm{km}$ target for passenger cars by 2012 as stated by the European Council-EC [11]. In particular, assuming this target met in 2012 and the cars are replaced at the same rate as today there will be an efficiency gain of 30 $\mathrm{g} \mathrm{CO}_{2}$ per km which corresponds to $-125 \mathrm{Mt} \mathrm{CO}_{2}-$ eq. [11]. Different targets, e.g. that band in the Bali roadmap in 2020, can guarantee additional emission reductions.

Consequently the main keyword as the way forward to a sustainability development is: integration. Integration of transport and environmental strategies; integration of vehicle efficiency targets, technologies, energy efficient transportation modes, construction and maintenance infrastructures, behavioural changes, reduction of transport demand. In particular, all EEA reports state "it will not be possible to achieve ambitious targets without limiting transport demand" [11]: modal shift and influence on user behaviours may reduce the need for demand that is the so-called transport volume.

This paper presents a set of original cost-based models and a DSS to solve the CPP. The proposed models and methods mainly refer to the clustering analysis (CA), which can be efficiently supported by commercial statistical tools. Therefore, these supporting decision models can be quickly adopted by mobility managers of industrial and service production systems implementing CP and other transportation modes to reduce traffic and emissions or by expertise offering and supplying mobility services.

Literature studies on CA as a way to group items, e.g. car poolers, is presented by [16] and [9] for respectively cellular manufacturing and group technology, by [17] for the analysis of enterprises network and by [8] for freight transportation and vehicle routing adopting the groupage strategy.

There are not recent studies on CP. Previous significant contributions are: [18] on daily CPP, [19] and finally [20]. [20] presents a case study in Strasbourg (France).

[2] presents an exact and a heuristic method for the CPP, based on two integer programming formulations. This manuscript is not an Operations Research contribution focused on the mathematical formulation of the problem and the development of optimal approaches to solve it, but it is focused on effective models and methods to face the generic problem instance and support the decision making efficiently. To this, a DSS is proposed and applied to a set of real instances.

\section{Cluster Based Approach to the CPP}

The adopted approach to solve the CPP is 2-phases: cluster first and route second. Nevertheless, it is based on three main activities, called steps, as illustrated in Figure 1.

\subsection{Step 1}

The first step deals with data collection about:

- Users, e.g. geographical locations, availability/non availability of a car to be shared, capacity of the car (i.e. maximum admissible number of passengers) and eventually maximum admissible extra time to reach the destination point, etc.;

- Destination point, i.e. geographical location;

- Transportation network by the availability of a geographical map, routes and related performance, e.g. 
average travelling velocity, as a result of route typology, e.g. HOV lanes, and traffic congestions.

\subsection{Step 2}

The second step is the first phase of the adopted 2-phases heuristic approach for the CPP. It is based on CA and on the use of similarity indices as introduced by statistics and widely applied to several disciplines, e.g. medicine, biology, engineering, economics ([8] and [9]). In particular, the level of similarity between two generic users who want to participate to a CP service is a measure of saving which encourages them to commuting, i.e. to belong to a shared group of people.

Figure 1 presents the main tasks to execute a CA and obtain the groups of users as a partition of the whole set of participants to a CP program. The second task of step 2 deals with the determination of the similarity matrix, as the result of the adoption of a similarity or dissimilarity index, also called "distance" (see task 1, called "saving analysis: similarity/distance evaluation" in Figure 1). An example of a similarity index between two locations $A$ and $B$ is the Pearson correlation coefficient defined as:

$$
\operatorname{Pearson}_{A, B}=\frac{\sum_{i=1}^{n}\left(x_{A, i}-\bar{x}_{A}\right) \cdot\left(x_{B, i}-\bar{x}_{B}\right)}{\sqrt{\sum_{i=1}^{n}\left(x_{A, i}-\bar{x}_{A}\right)^{2} \cdot \sum_{i=1}^{n}\left(x_{B, i}-\bar{x}_{B}\right)^{2}}}
$$

where

$$
i=I, \cdots, n \text { locations }
$$

$n$ : number of users (participants)

$X_{i, j}$ : distance between location $i$ and location $j$

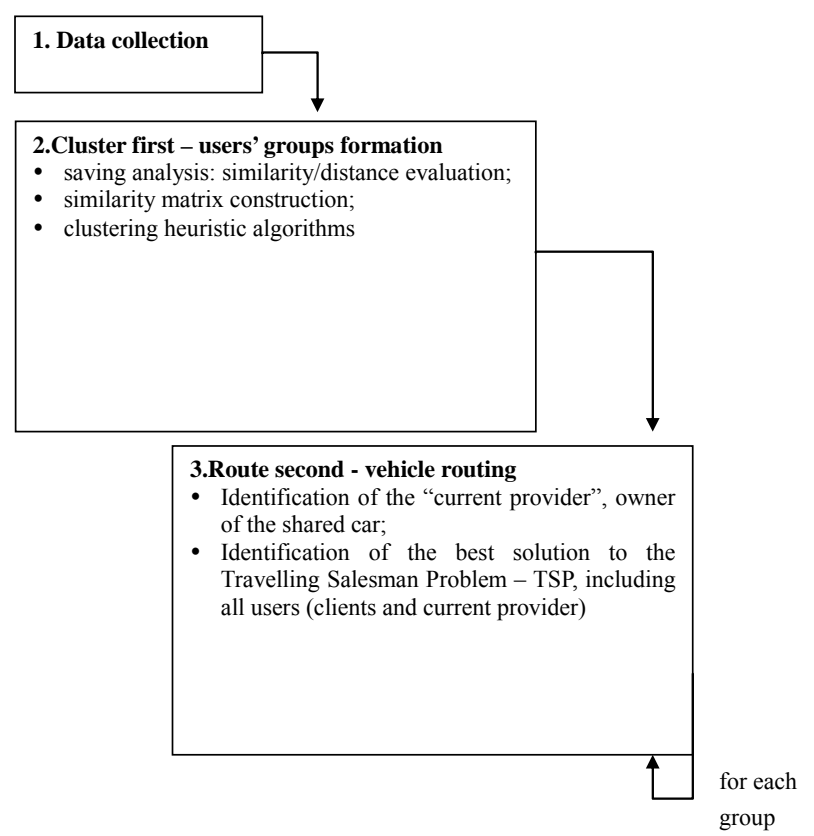

Figure 1. Three steps-2-phases approach to the CPP. $\bar{x}_{i}$ mean distance of $n-1$ users from the $i$ location.

This index does not consider the location of the destination point, but the distance between two addresses as CP users' locations. Nevertheless, the aim of a CA is to support the grouping of users, i.e. the hierarchical partitioning of the whole set of participants. Other similar indices are reported, applied and discussed by [16] which deals with cellular manufacturing, and by [8] and [9] discussing freight transportation. These problem-oriented similarity indices are not the object of this manuscript.

The third task of this step ("cluster first" phase) deals with the process of grouping the participants in homogeneous clusters, called car pools. The basic hypothesis is that given a generic group, the driver of the shared car turns among the participants: in case the pool is made of five participants and the number of working days is five, the single user shares and drives his/her own car one day each week. Nevertheless, the proposed approach, models and DSS can be also applied in case the grouping process is executed daily in accordance to a continuous changing of the set of participants, eventually owner of cars of different capacities. The clustering process is executed by the application of a heuristic algorithm, e.g. the Complete Linkage (CLINK) clustering also known as Nearest Neighbour algorithm, the Single Linkage (SLINK) clustering, also available in commercial statistical tools, e.g. Minitab $^{\circledR}$ statistical software and Statgraphics ${ }^{\circledR}$. Consequently, a rough execution of these decisional tasks for the group formation can be also executed both by not expert mobility managers of companies encouraging CP and by transportation agencies or $\mathrm{CP}$ service suppliers. Next section illustrates a DSS developed by the author for the sequential and automatic execution of these steps.

\subsection{Step 3}

The third step is the second phase of the adopted 2-phase approach to the CPP. Aim of this step is the identification of best set of daily routes to reach the destination location by the adoption of the groups of travellers previously defined. The generic route depends on the selection of a user, named "current provider" of the group. The current provider is the owner and driver of the vehicle. He/she visits his/her colleagues' members of the same group and travels to the destination point. This is the well-known travelling salesman problem (TSP) given the starting and ending locations to visit in a single trip.

\section{A Decision Support System for the CPP}

This section illustrates an original DSS, named "The Carpooler", developed by the author to support the mobility manager in the $\mathrm{CP}$ activity. Figure 2 presents the main graphical user interface (GUI), which introduces the user to the data entry activity, the parameterization of 


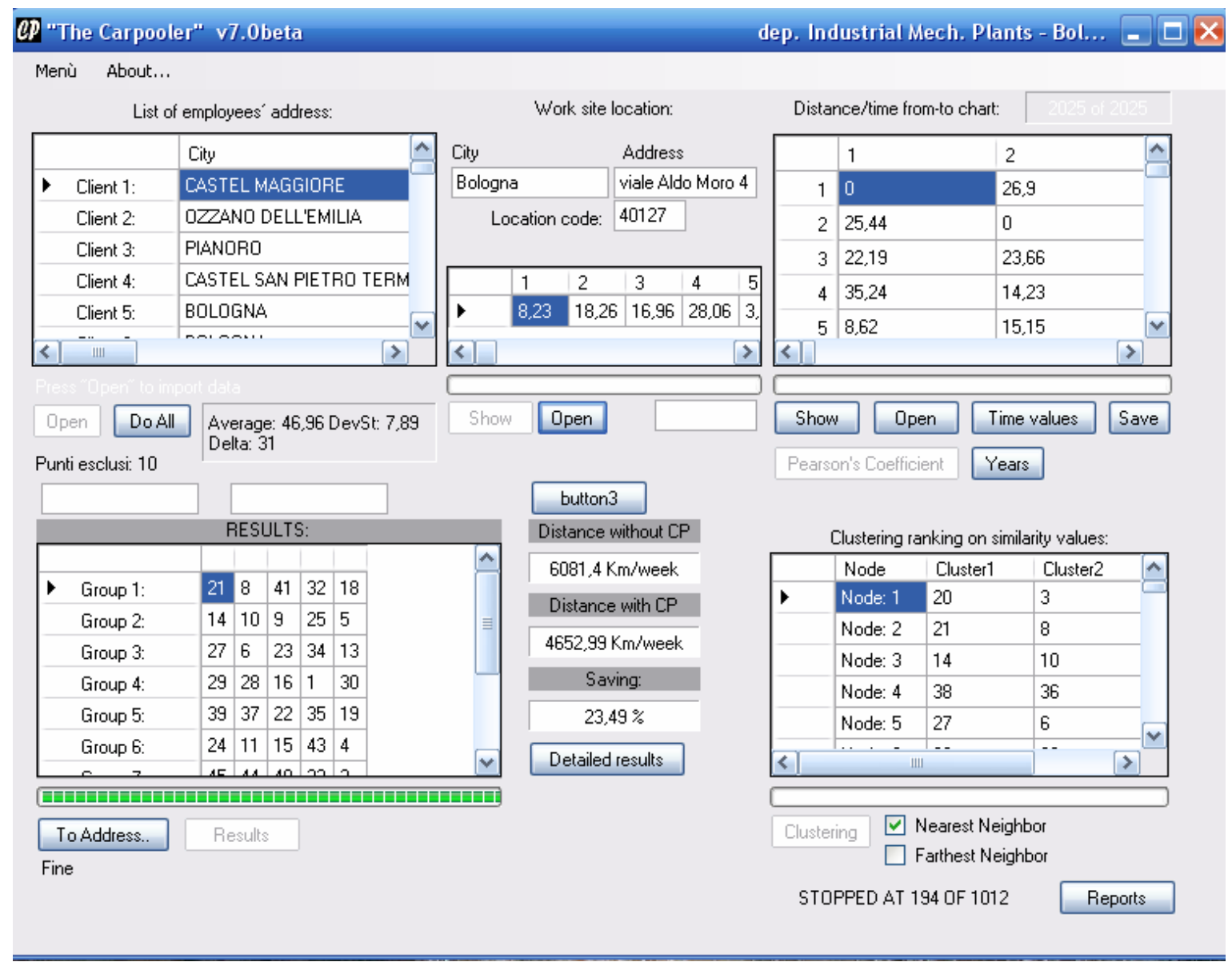

Figure 2. Main GUI of “the carpooler”.

the clustering and routing processes, and to follow the interactive sequence of decisional steps as illustrated in previous section.

Figure 3 presents the GUI for setting the parameters necessary to execute the CP. These parameters deal with:

- Routing Strategy. Shortest or Quickest, to identify the shortest or the quickest path between two generic locations. The first strategy minimizes the travelled distance; the quickest minimizes the travel time. The adoption of a specific routing strategy generates a from-to chart of transportation costs. The transportation cost between two locations is minimum in terms of time or distance, andis evaluated by adopting one of the rules proposed by Operations Research to solve the Shortest Path Problem (SPP) [21].

- Clustering Rule. e.g. CLINK or SLINK (see Section 3 ). This is the similarity based heuristic rule generating the groups of users as a partition of the whole set of CP participants. Nevertheless these basic rules, well-known and discussed by the large amount of literature studies, have been be properly modified in order to generate groups of car poolers respecting a maximum admissible and capacity of vehicles.
- Time-Based or Distance-Based Analyses. This choice deals with the evaluation method to quantify and analyze the transportation cost between two generic locations, in agreement with the time or distance "from to charts" including all users and exemplified in Figure 2.

- Age-Based Modification. The proposed DSS also introduces the option to adjust the similarity index measure by the introduction of a corrective factor which encourages the formation of homogeneous groups of CP participants in accordance to one or more attributes of poolers, e.g. age, sex, hobby. For example the so-called age-based similarity index Pearson_age ${ }_{i j}$ is the result of the introduction of a correction to the standard value of similarity between two generic car poolers $i$ and $j$ :

$$
\left\{\begin{array}{l}
\text { Pearson_age }(\varepsilon)_{i j}=\text { Pearson }_{i j} \cdot \max _{\operatorname{age}(j) \geq \operatorname{age}(i)}\left\{\varepsilon, \frac{\operatorname{age}(i)}{\operatorname{age}(j)}\right\} \\
\varepsilon \in(0,1]
\end{array}\right.
$$

where $\varepsilon$ maximum admissible correction to the standard Person index in Equation (1). 
- Threshold Level of Similarity. This introduces a modification in the standard clustering heuristic algorithm, e.g. CLINK and SLINK. Given two entities $A$ and $B$, e.g. two passengers or under construction groups of passengers, both candidate to be clustered in a same group with a level of similarity $S_{A, B}$, the clustering is admissible if the level of similarity between them is not lower than the threshold value.

- Further Parameters. They deal with driving speed, unit costs, start driving time, etc. (see Figure 4).

The GUI in Figure 2 is made of a few main "sections":

- Data Entry Section. On Locations: the address of the destination and users' locations, named employees' addresses, are reported. An example is "viale Aldo Moro 4-40127" in Figure 2. The capacity of the generic vehicle in terms of the maximum admissible

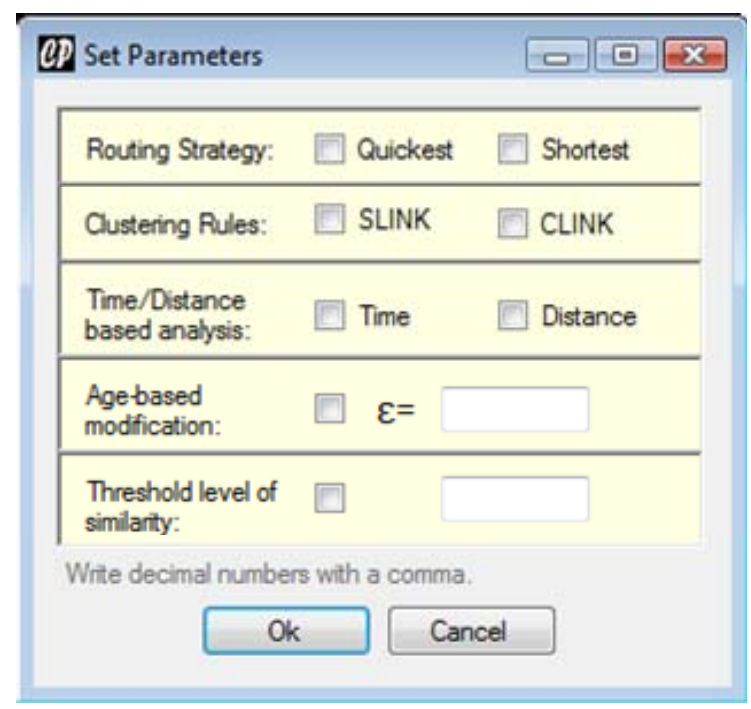

Figure 3. GUI set parameters.

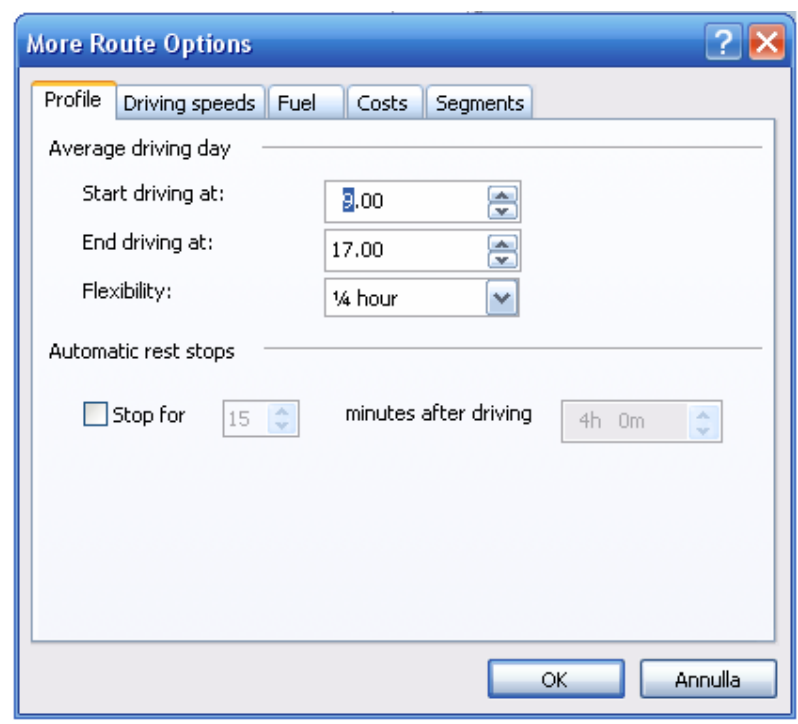

Figure 4. Additional secondary parameters. number of travelling persons is another important input parameter. This integer number usually belongs to the range $[5,8]$.

- Similarity Evaluation Section. It reports the similarity matrix as the result of the adoption of a similarity index, e.g. Pearson. In particular, a list of "clustering nodes" as the result of the clustering ranking analysis is reported (see the "Clustering ranking on similarity values" in Figure 2). The list of nodes generated by the grouping process is reported. A well know graphical illustration of this degradation process of grouping and partitioning is the dendrogram, which is illustrated and exemplified by [8].

- Grouping Formation Section. It presents the composition of the obtained car pools, i.e. the configuration of the sets partitioning the group of participants to the CP program.

- Trips Definition Section. It presents the sequence of visits in the generic group of employees for each group and for all current providers (daily trips). These results are not explicitly reported in the main frame illustrated in Figure 2, but are accessible pressing the button "Detailed results" as exemplified in Figure 5.

- Performance Evaluation Section. It reports many indices measuring and comparing the performance of $\mathrm{CP}$ solutions. Some of them are accessible in the detail results (Figure 5). The most important indices are:

- Transportation cost in terms of time, e.g. hours, or distance, e.g. kilometres, in absence of $\mathrm{CP}$ or in presence of CP. A cost saving is expected, otherwise the CP solution is not suitable.

- Reduction of the number of cars. A reduction in the number of cars travelling is expected by the adoption of the sharing strategy.

- Composition of the generic group, in terms of current provider and "current clients". The provider generally changes passing from one working day to another: he/she uses his/her owned car to reach the work location previously visiting the other members of the group.

- "Trip to work" of each group, i.e. given a pool and a current provider it defines the sequence of visits. This is called the "current sequence" of visits.

- Cost increase (penalties) for the generic user. This is the cost a user has to accept renouncing to travel alone to the work site and adopting a CP strategy. Obviously, this cost is day dependent, i.e. it depends on the current provider and current clients, the sequence of visits, and the admissible routing performance of vehicles (e.g. average velocity) and routes of the network (e.g. maximum admissible velocity). The case study illustrated below introduces a set of indices to properly measure this increase and possible weekly savings due to $\mathrm{CP}$. 


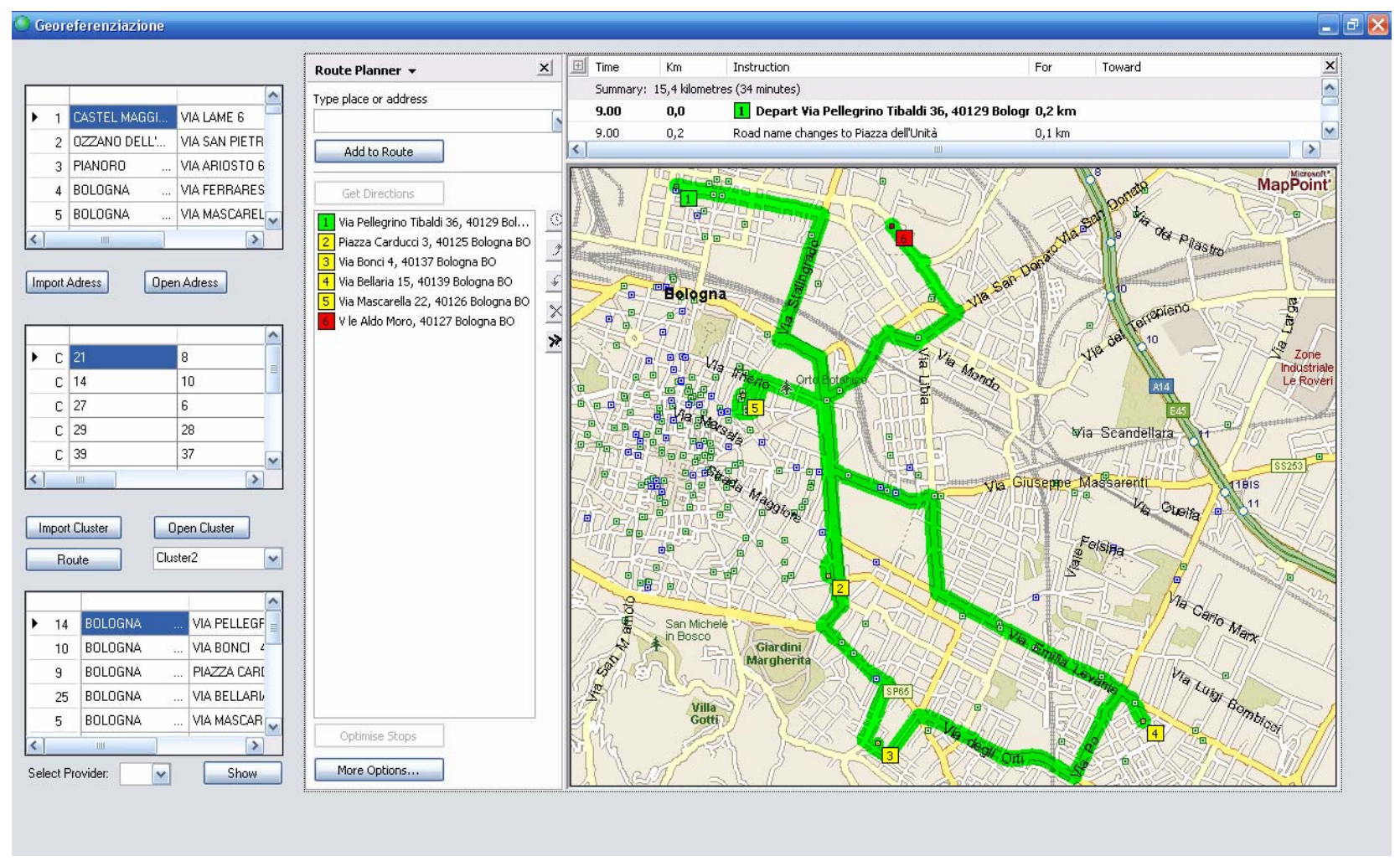

Figure 5. Detailed results. Route planner.

The DSS presents the obtained results on a geographical map including the multi-stop trips of vehicles visiting the clients' members of the car pools given a set of current providers. Figure 5 exemplifies a view of a map generated by the tool and illustrating an exemplifying trip. It refers to an Italian case study properly introduced and discussed below.

\section{Case Study}

This section presents a case study where the proposed approach to solve the CPP has been applied adopting different settings. The obtained results in different whatif scenarios have been properly compared.

This case study refers to the existing administrative offices of an Italian public institution. The institution object of the analysis counts about 3000 employees and many sites whose 15 are located in the capital city of Bologna. The number of employees who are potential participants of a CP program and are the object of this case study is about 1900 because many people come from outside the city of Bologna and use the train.

Figure 6 reports a zoomed map of the Italian city of Bologna with the locations of origin object of the analysis: the dots identify the starting points, i.e. the addresses of the employees participating to the program, grouped for different colours that correspond to specific destination points, which are the working site locations mod- elled as flags. In particular, red colour models the locations of employees, about one hundred, who daily go to the work site named "Bologna, via A. Moro".

\subsection{A Working Site with 98 Employees}

This section illustrates a brief discussion of the results obtained by the application of the proposed models and DSS to the CPP for the instance of 98 employees (see Figure 7, reference "A. Moro, Bologna").

Four different simulations have been conducted by the adoption of a specific shortest path problem evaluation, the previously called quickest and shortest routing strategies, combined to a clustering process conducted on a from-to data sheet that collects travelling times or travelling distances between couples of locations. The following notation is adopted:

- SIM_1: from-to data sheet of times combined to the quickest strategy;

- SIM 2: from-to data sheet of distances combined to the quickest strategy;

- SIM_3: from-to data sheet of times combined to the shortest strategy;

- SIM 4: from-to data sheet of distances combined to the shortest strategy.

The combination of different similarity indices, routing strategies, and data sheet types generates a large set of results. Table 1 reports the summarized results related 


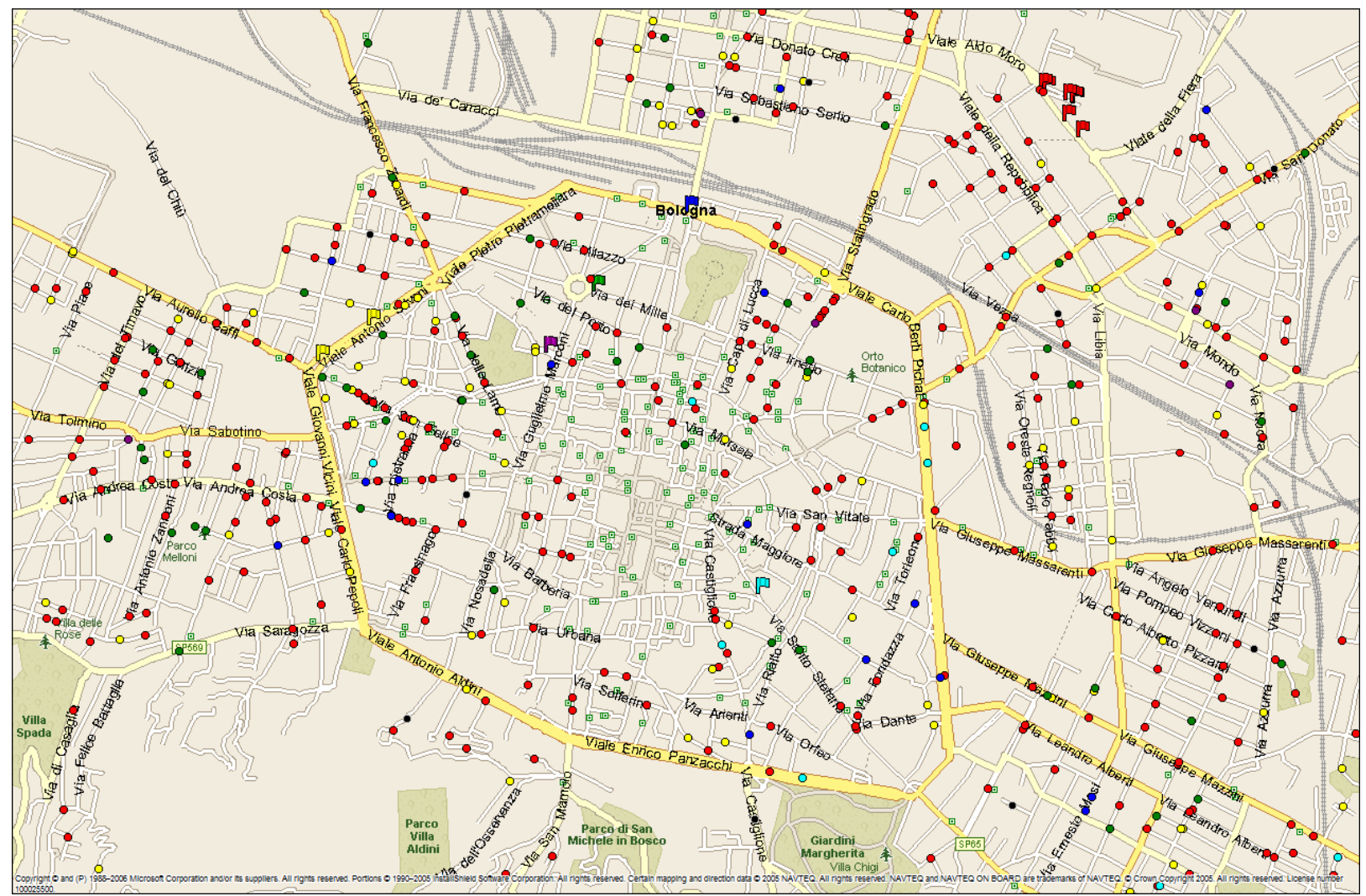

Figure 6. Working locations (flags) and employees' addresses (dots).

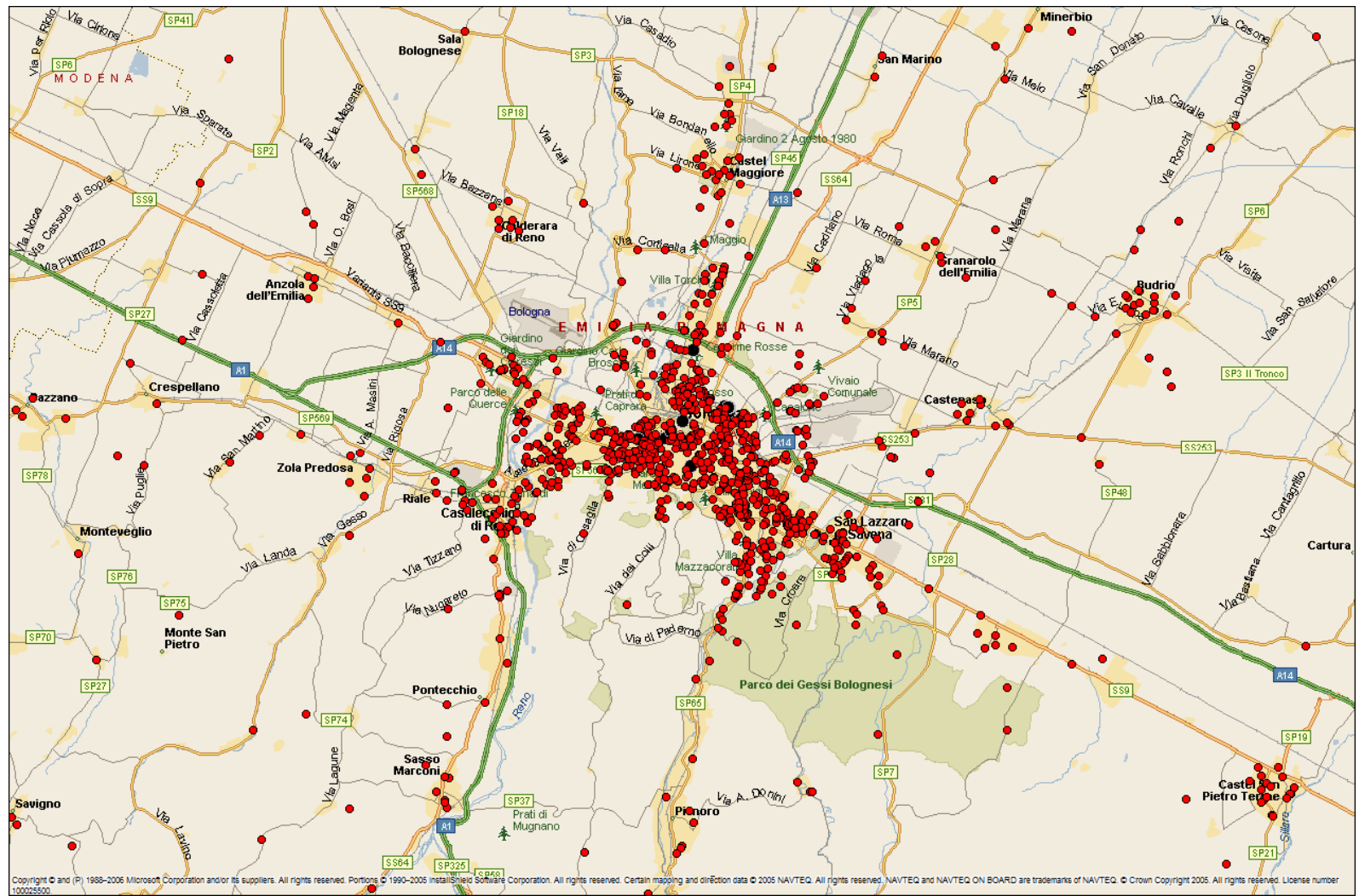

Figure 7. Site “A. Moro, Bologna”, 98 employees. 
Table 1. Site “A. Moro, Bologna”, 98 employees. Multi scenarios analysis. SLINK rule.

\begin{tabular}{|c|c|c|c|c|c|c|c|c|c|c|}
\hline Simulation & $\begin{array}{l}\text { Routing } \\
\text { strategy }\end{array}$ & $\begin{array}{c}\text { Clustering } \\
\text { on }\end{array}$ & $\begin{array}{l}\text { Similarity } \\
\text { index }\end{array}$ & $\begin{array}{c}\text { Distance no } \\
\text { CP } \\
{[\mathrm{km} \mid \text { week }]}\end{array}$ & $\begin{array}{c}\text { Distance with } \\
\text { CP } \\
{[\mathrm{km} \backslash \text { week }]}\end{array}$ & $\begin{array}{c}\text { Saving } \\
\text { distance } \\
{[\%]}\end{array}$ & $\begin{array}{c}\text { Time no } \\
\text { CP } \\
{[\text { min } \backslash \text { week] }}\end{array}$ & $\begin{array}{l}\text { Time with } \\
\text { CP } \\
\text { [min } \backslash \text { week] }\end{array}$ & $\begin{array}{c}\text { Saving } \\
\text { time } \\
{[\%]} \\
\end{array}$ & $\begin{array}{c}\text { Average } \\
\text { velocity } \\
{[\mathrm{km} / \text { hour }]}\end{array}$ \\
\hline \multirow{3}{*}{ SIM_1 } & \multirow{3}{*}{ Quickest } & \multirow{3}{*}{ Times } & Pearson & 10,818 & 8699 & 19.58 & 13,167 & 11,078 & 15.86 & 42.39 \\
\hline & & & $\begin{array}{l}\text { Pearson_age } \\
\quad(0.6)\end{array}$ & 10,818 & 9757 & 9.80 & 13,167 & 11,881 & 9.77 & 43.76 \\
\hline & & & $\begin{array}{l}\text { Pearson_age } \\
\quad(0.75)\end{array}$ & 10,818 & 9701 & 10.32 & 13,167 & 11,786 & 10.49 & 43.41 \\
\hline \multirow{3}{*}{ SIM_2 } & \multirow{3}{*}{ Quickest } & \multirow{3}{*}{ Distances } & Pearson & 10,818 & 8577 & 20.72 & 13,167 & 10,366 & 21.27 & 42.31 \\
\hline & & & $\begin{array}{c}\text { Pearson_age } \\
\quad(0.6)\end{array}$ & 10,818 & 9330 & 13.75 & 13,167 & 11,542 & 12.34 & 44.44 \\
\hline & & & $\begin{array}{l}\text { Pearson_age } \\
\quad(0.75)\end{array}$ & 10,818 & 8929 & 17.46 & 13,167 & 11,177 & 15.11 & 42.91 \\
\hline \multirow{3}{*}{ SIM_3 } & \multirow{3}{*}{ Shortest } & \multirow{3}{*}{ Times } & Pearson & 9081 & 6195 & 31.78 & 17,662 & 12,421 & 29.67 & 27.42 \\
\hline & & & $\begin{array}{c}\text { Pearson_age } \\
(0.6)\end{array}$ & 9081 & 9160 & -0.88 & 17,662 & 17,159 & 2.85 & 28.19 \\
\hline & & & $\begin{array}{l}\text { Pearson_age } \\
\quad(0.75)\end{array}$ & 9081 & 6900 & 24.01 & 17,662 & 13,264 & 24.90 & 27.30 \\
\hline \multirow{3}{*}{ SIM_4 } & \multirow{3}{*}{ Shortest } & \multirow{3}{*}{ Distances } & Pearson & 9081 & 7069 & 22.16 & 17,662 & 13,675 & 22.58 & 27.79 \\
\hline & & & $\begin{array}{c}\text { Pearson_age } \\
(0.6)\end{array}$ & 9081 & 8753 & 3.61 & 17,662 & 16,955 & 4.00 & 28.43 \\
\hline & & & $\begin{array}{c}\text { Pearson_age } \\
\quad(0.75)\end{array}$ & 9081 & 8640 & 4.85 & 17,662 & 16,814 & 4.80 & 28.77 \\
\hline
\end{tabular}

to the expected distance $[\mathrm{km} /$ week] and time [min/week] of vehicles routes when $\mathrm{CP}$ is adopted and when $\mathrm{CP}$ is not adopted. Table 1 compares the performance of three different similarity indices: Pearson, Pearson_age (0.6) and Pearson age (0.75). Last two similarity indices are defined in accordance to Equation (2), where $\varepsilon$ is assumed 0.6 and 0.75 respectively.

Table 1 reports also the expected values of the average velocity $[\mathrm{km} /$ hours $]$ defined as the mean measure calculated for all clusters generated. The quickest strategy guarantees savings greater than $9 \%$ both in terms of time and distance, while shortest strategy best performs adopting the Pearson index and clustering on time (about $30 \%$ of saving). The modified Pearson_age $(0.60)$ combined to the clustering process conducted on times generates a negative saving in terms of distance. Pearson performs better when clustering is conducted on times (distances) and saving is measured in terms of distance (time). The standard Pearson index performs better than the other two modified indices, whose major advantage is to guarantee more homogeneous groups in term of participants' age. Last column demonstrates that the shortest routing strategy generates lower values of the average velocity of vehicles.

Table 2 reports the expected values, quantified on the whole set of 98 employees, of the following performance indicators and for different simulated scenarios:
- $T 1$, standardized extra daily load on time defined as the mean value of:

$$
T 1_{i}=\frac{t_{i \text { provider, } \mathrm{CP}}(\text { day })}{t_{i \text { no, CP }}(\text { day })}
$$

where

$t_{i \text { provider,CP }}$ (day) daily time [min/day] if employee $i$ uses his/her owned vehicle, as a "provider", and adopts CP;

$t_{i \text {,n CP }}$ (day) daily time[min/day] if $i$ travels alone, i.e. $\mathrm{CP}$ is not adopted.

Obviously $t_{i, \text { no CP }}$ (day) $\leq t_{i \text { provider,CP }}$ (day) because the employee, as a provider, is forced to increase the time spent on board renouncing to take the shortest path to go to work and accepting to bring up at least a colleague.

- $T 2$, standardized weekly saving time defined as the mean value of:

$$
\begin{aligned}
T 2_{i} & =\frac{t_{i \text { provider }, \mathrm{CP}}(\text { week })}{t_{i \mathrm{no}, \mathrm{CP}}(\text { week })} \\
& =\frac{\left[t_{i \text { provider }, \mathrm{CP}}(\text { day })\right] \frac{n_{\text {day }}}{\text { vehicle }_{\text {capacity }}}}{t_{i \mathrm{no}, \mathrm{CP}}(\text { day }) \cdot n_{\mathrm{day}}}
\end{aligned}
$$

where

$t_{\text {iprovider,CP }}$ (week) weekly cost [min/week] adopting CP and assuming $i$ as the provider all week long 
Table 2. Site “A. Moro, Bologna”, 98 employees. Extra daily load and weekly saving in terms of time and distance. SLINK rule.

\begin{tabular}{|c|c|c|c|c|c|}
\hline Simulation & Similarity index & $\begin{array}{l}\text { T1: Average std. extra } \\
\text { daily load on time }\end{array}$ & $\begin{array}{c}T 2: \text { Average std. } \\
\text { weekly saving time }\end{array}$ & $\begin{array}{l}D 1 \text { : Average std. extra } \\
\text { daily load on distance }\end{array}$ & $\begin{array}{l}\text { D2: Average std. weekly } \\
\text { saving distance }\end{array}$ \\
\hline \multirow{3}{*}{ SIM_1 } & Pearson & 5.18 & 0.85 & 5.19 & 1.12 \\
\hline & Pearson_age (0.6) & 5.35 & 0.90 & 5.37 & 1.14 \\
\hline & Pearson_age $(0.75)$ & 5.13 & 0.85 & 5.15 & 1.09 \\
\hline \multirow{3}{*}{ SIM_2 } & Pearson & 4.80 & 0.82 & 4.77 & 1.03 \\
\hline & Pearson_age (0.6) & 5.33 & 0.87 & 5.30 & 1.12 \\
\hline & Pearson_age $(0.75)$ & 4.97 & 0.75 & 5.21 & 1.07 \\
\hline \multirow{3}{*}{ SIM_3 } & Pearson & 4.17 & 0.40 & 4.13 & 0.87 \\
\hline & Pearson_age (0.6) & 4.17 & 0.40 & 5.53 & 1.13 \\
\hline & Pearson_age $(0.75)$ & 4.40 & 0.41 & 4.38 & 0.89 \\
\hline \multirow{3}{*}{ SIM_4 } & Pearson & 5.67 & 0.58 & 5.64 & 1.16 \\
\hline & Pearson_age (0.6) & 6.79 & 0.69 & 6.73 & 1.39 \\
\hline & Pearson_age $(0.75)$ & 6.76 & 0.71 & 6.71 & 1.42 \\
\hline
\end{tabular}

$t_{i, \text { no CP }}$ (week) weekly time [min/week] if $i$ travels alone, i.e. $\mathrm{CP}$ is not adopted vehicle ${ }_{\text {capacity }}$ number of passenger per vehicle. This is the number of employees in the group whose provider $i$ is a member

$n_{\text {day }}$ number of working days in a week.

- $D 1$, standardized extra daily load on distance defined as the mean value of:

$$
D 1_{i}=\frac{d_{i \text { provider }, \mathrm{CP}}(\text { day })}{d_{i \mathrm{no}, \mathrm{CP}}(\text { day })}
$$

where

$d_{i \text { provider,CP }}$ (day) daily distance [ $\mathrm{km} /$ day] if employee $i$ uses his/her owned vehicle, as a provider, and adopts CP;

$d_{i \text {, no CP }}$ (day) daily distance $[\mathrm{km} /$ day] if $i$ travels alone,

i.e. $\mathrm{CP}$ is not adopted.

It is similar to $T 1$ defined by Equation (3).

- D2, standardized weekly saving distance defined as the mean value of:

$$
\begin{aligned}
D 2_{i} & =\frac{d_{i \text { provider } \mathrm{CP}}(\text { week })}{d_{i \text { no, } \mathrm{CP}}(\text { week })} \\
& =\frac{\left[t_{i \text { provider } \mathrm{CP}}(\text { day })\right] \frac{n_{\text {day }}}{\text { vehicle }_{\text {capacity }}}}{t_{i \text { no, } \mathrm{CP}}(\text { day }) \cdot n_{\text {day }}}
\end{aligned}
$$

where

$d_{i \text { provider,CP }}($ week) weekly global distance $[\mathrm{km} / \mathrm{week}]$ travelled by the car pool if the employee $i$ uses his/her owned vehicle, as a provider. $i$ is assumed to be the provider all weeklong;

$d_{i, \text { no CP }}$ (week) weekly distance $[\mathrm{km} /$ week] if $i$ travels alone, i.e. $\mathrm{CP}$ is not adopted.

The following numerical example clarifies these results. Consider an exemplifying car pool made of 3 participants, called $A, B$ and $C$. Table 3 reports the values of distance for $i$ in presence (and absence) of CP. $T 1$ and $T 2$ are the result of the application of Equations (3) and (4). $T 1$ values result greater than 1 and $T 2$ lower than 1 .

Given a passenger $i, T 1_{i}$ and $D 1_{i}$ are usually greater than 1 because the $\mathrm{CP}$ strategy asks the provider to increase the cost of travelling: he/she does not travel alone but visits a subset of his/her colleagues, the clients, as members of the belonging sheared pool.

$T 2_{i}\left(D 2_{i}\right)$ lower than 1 means that the expected cost of CP is lower than the "alone" strategy, whose cost is generated in absence of CP. Another hypothesis is that the provider of the car pool is always the passenger " $i$ ". For this reason we call $T 2_{i}$ and $D 2_{i}$ "weekly savings". Nevertheless, given a pool (or a set of pools), the real travelling saving of time and/or distance on a significant period of time $T$, e.g. a week or a month, is guaranteed by the contributions of all participants to the pool (or the set of pools) as turning providers: the current provider can suffer to increase his/her cost travelling to work, but he/she takes advantages of participating as a client when the other passengers of his/her group use their owned cars as new current providers. $T 2_{i}\left(D 2_{i}\right)$ is greater than one when the $\mathrm{CP}$ strategy is not convenient and the current provider does not turn (he/she remains the same all week long).

These indices are expected to be lower as possible, that is the owner of the generic car, as a provider, does not stay too much time on board to visit and "collect" 
his/her colleagues, and in a week the CP strategy guarantees a saving cost.

The CP strategy obviously increases the time and distance spent to go to the work site renouncing to travel alone and to choose the shortest path. In particular, $T 1$ and $D 1$ demonstrate that the provider has to use his/her vehicle for a distance (time) up to 6 - 7 times the distance (time) necessary to go to work alone. Nevertheless, the CP strategy significantly reduces the number of simultaneously travelling vehicles from the worst hypothesis of 98 cars (all 98 passengers are travelling alone), to 20-22 (see Table 4) when the admissible number of passengers per vehicles is the optimistic value equal to five. This guarantees also a global saving in travelled distance and time as already discussed and shown in Table $\mathbf{1 .}$

\subsubsection{Vehicle Capacity and Threshold Similarity Level}

This paragraph reports main results obtained by the availability of low capacity vehicles and the introduction of a modification of the clustering rule based on different values of the free parameter "threshold level of similarity" (introduced in Section 4). Table 5 reports the results obtained by the application of the $\mathrm{CP}$ similarity based strategy in the simulated scenarios SIM_1 and assuming a vehicle capacity equal to 3 . Different values of $\varepsilon, 0.6$ and 0.75 , are considered by the introduction of the age-based modification and the application of equation (2). Obviously comparing these results with previous ones, obtained for a capacity equal to 5 and illustrated in tables from 1 to 4 , the number of pool increases and the expected savings in terms of time and distance decrease.

Table 6 reports the results obtained by simulation SIM_1 introducing a modification in the standard heuristic algorithm SLINK. The introduction of a threshold level of similarity, as introduced in Section 4, significantly increases the performance of the CP: the percentage saving on distance passes from about $10 \%$ to more than $20 \%$, and about $18 \%$ in terms of time. The number of generated pools does not significantly change.

Table 3. $T 1$ and $T 2$ evaluation, a numerical example.

\begin{tabular}{|c|c|c|c|c|c|c|}
\hline Employee location $i$ & $d_{i \text { provider, } \mathrm{CP}}($ day) & $d_{i, \text { no CP }}($ day) & $d_{i \text { provider,CP }}$ (week) & $d_{i, \text { no CP }}($ week) & $T 1_{i}$ & $T 2_{i}$ \\
\hline$A$ & 105.9 & 81.4 & 176.5 & 407.0 & 1.301 & 0.434 \\
\hline$B$ & 124.4 & 87.1 & 207.3 & 435.6 & 1.428 & 0.476 \\
\hline C & 125.0 & 62.3 & 208.4 & 311.3 & 2.008 & 0.669 \\
\hline
\end{tabular}

distances in $[\mathrm{km}]$

Table 4. Site “A. Moro, Bologna”, 98 employees. Numbers of pools and number of passengers per pool. Vehicle capacity = 5 . SLINK rule.

\begin{tabular}{|c|c|c|c|c|c|c|c|c|}
\hline \multirow{2}{*}{ Simulation } & \multirow{2}{*}{ Similarity index } & \multirow{2}{*}{ Number of pools } & \multicolumn{5}{|c|}{ Pool dimension } & \multirow{2}{*}{ Average number of employers per pool } \\
\hline & & & $1($ no $C P)$ & 2 & 3 & 4 & 5 & \\
\hline \multirow{3}{*}{ SIM_1 } & Pearson & 22 & 0 & 0 & 2 & 8 & 12 & 4.45 \\
\hline & Pearson_age (0.6) & 21 & 0 & 0 & 1 & 5 & 15 & 4.67 \\
\hline & Pearson_age $(0.75)$ & 21 & 0 & 0 & 1 & 5 & 15 & 4.67 \\
\hline \multirow{3}{*}{ SIM_2 } & Pearson & 22 & 0 & 0 & 3 & 6 & 13 & 4.45 \\
\hline & Pearson_age (0.6) & 21 & 0 & 1 & 1 & 2 & 17 & 4.57 \\
\hline & Pearson_age $(0.75)$ & 20 & 0 & 0 & 0 & 2 & 18 & 4.9 \\
\hline \multirow{3}{*}{ SIM_3 } & Pearson & 21 & 0 & 0 & 1 & 5 & 15 & 4.67 \\
\hline & Pearson_age (0.6) & 20 & 1 & 0 & 1 & 1 & 18 & 4.85 \\
\hline & Pearson_age $(0.75)$ & 20 & 0 & 0 & 0 & 2 & 18 & 4.9 \\
\hline \multirow{3}{*}{ SIM_4 } & Pearson & 21 & 0 & 0 & 3 & 3 & 16 & 4.8 \\
\hline & Pearson_age (0.6) & 21 & 0 & 0 & 3 & 3 & 16 & 4.8 \\
\hline & Pearson_age $(0.75)$ & 22 & 0 & 1 & 3 & 3 & 15 & 4.36 \\
\hline
\end{tabular}


Table 5. Site “A.Moro, Bologna”. Expected savings assuming vehicle capacity equal to 3 for different similarity indices, simulation SIM_1 \& SLINK rule.

\begin{tabular}{|c|c|c|c|c|c|c|c|c|c|c|}
\hline Simulation & $\begin{array}{l}\text { Vehicle } \\
\text { capacity }\end{array}$ & $\begin{array}{l}\text { Similarity } \\
\text { index }\end{array}$ & $\begin{array}{c}\text { Number } \\
\text { of } \\
\text { pools }\end{array}$ & $\begin{array}{l}\text { Employees } \\
\text { travelling } \\
\text { alone }\end{array}$ & $\begin{array}{c}\text { Distance } \\
\text { with no CP } \\
{[\mathrm{km} / \text { week }]}\end{array}$ & $\begin{array}{c}\text { Distance } \\
\text { with CP } \\
{[\mathrm{km} / \text { week }]}\end{array}$ & $\begin{array}{c}\text { Saving on } \\
\text { distance } \\
{[\%]}\end{array}$ & $\begin{array}{c}\text { Time with } \\
\text { no CP } \\
\text { [min/week] }\end{array}$ & $\begin{array}{c}\text { Time with } \\
\text { CP } \\
\text { [min/week] }\end{array}$ & $\begin{array}{c}\text { Saving } \\
\text { on time } \\
{[\%]}\end{array}$ \\
\hline \multirow{3}{*}{ SIM_1 } & \multirow{3}{*}{3} & Pearson & 35 & 1 & 10,818 & 9630 & 10.98 & 13,167 & 11,848 & 10.01 \\
\hline & & $\begin{array}{c}\text { Pearson_age } \\
(0.6)\end{array}$ & 34 & 0 & 10,818 & 10,083 & 6.79 & 13,167 & 12,376 & 6.00 \\
\hline & & $\begin{array}{c}\text { Pearson_age } \\
(0.75)\end{array}$ & 34 & 0 & 10,818 & 10,008 & 7.48 & 13,167 & 12,357 & 6.15 \\
\hline
\end{tabular}

Table 6. Site “A. Moro, Bologna”. Expected savings assuming vehicle capacity equal to 3 for different similarity thresold, simulation SIM_1 \& Pearson similarity index. SLINK rule.

\begin{tabular}{|c|c|c|c|c|c|c|c|c|c|c|}
\hline Simulation & $\begin{array}{l}\text { Vehicle } \\
\text { capacity }\end{array}$ & $\begin{array}{l}\text { Similarity } \\
\text { threshold }\end{array}$ & $\begin{array}{l}\text { Number } \\
\text { of pools }\end{array}$ & $\begin{array}{l}\text { Employees } \\
\text { travelling } \\
\text { alone }\end{array}$ & $\begin{array}{c}\text { Distance } \\
\text { with no CP } \\
{[\mathrm{km} / \text { week }]}\end{array}$ & $\begin{array}{c}\text { Distance } \\
\text { with CP } \\
{[\mathrm{km} / \text { week }]}\end{array}$ & $\begin{array}{c}\text { Saving } \\
\text { on distance } \\
{[\%]}\end{array}$ & $\begin{array}{l}\text { Time with } \\
\text { no CP } \\
\text { [min/week] }\end{array}$ & $\begin{array}{c}\text { Time with } \\
\text { CP } \\
{[\mathrm{min} / \text { week }]}\end{array}$ & $\begin{array}{c}\text { Saving } \\
\text { on time } \\
{[\%]}\end{array}$ \\
\hline \multirow{3}{*}{ SIM_1 } & \multirow{3}{*}{3} & Standard & 35 & 1 & 10,818 & 9630 & 10.98 & 13,167 & 11,848 & 10.01 \\
\hline & & $\begin{array}{c}\text { Threshold } \\
0.8\end{array}$ & 35 & 5 & 10,818 & 8575 & 20.73 & 13,167 & 10,726 & 18.54 \\
\hline & & $\begin{array}{c}\text { Threshold } \\
0.9\end{array}$ & 34 & 7 & 10,818 & 8610 & 20.4 & 13,167 & 10,720 & 18.58 \\
\hline
\end{tabular}

These results demonstrate that the introduction of the proposed modification on the pooling heuristic rule better performs the group formation process. Consequently, it gives the system administrator the opportunity to best tune the problem settings in order to control the expected performance. Furthermore, higher quality groupings can be adopted without changing the number of generated groups.

Finally, this trivial modification on the standard version of the heuristic algorithms demonstrates that it is possible to conduct an effective clustering process of users simply modifying existing rules also implemented by several commercial tools.

Table 7 presents the obtained mean expected values of $D 1, D 2, T 1$ and $T 2$ for SIM_1, no threshold modification, different threshold similarity values (equal to 0.8 and 0.9 ), and two different values of vehicle capacity (equal to 3 and 5).

The adoption of lower capacity vehicles guarantees lower values of $D 1$ and $T 1$. In addition, the introduction of a threshold based modification of the clustering rule guarantees also lower values of $D 2$ and T2, i.e. more saving car pools.

All results illustrated so far refer to the adoption of the single linkage cluster method (SLINK), well known as the nearest-neighbour rule: the grouping process is the result of a ranking classification of a set of nodes in accordance with the level of similarity associated to each node. The single node refers to a couple of items, which correspond to two distinct pools of participants to be grouped. Adopting the SLINK, the similarity level is the highest value between all couples of users, one belonging to the first pool and one belonging to the second. Consequently, the standard version of SLINK can generate clusters not homogeneous because of the well-known literature "chaining" problem: a high level of similarity between couples of participants does not guarantee that all the members (i.e. all couples) of a same CP cluster are located closed one to the other. Different results are expected adopting the CLINK rule and eventually introducing the threshold similarity value: they can guarantee to control the levels of similarity for the whole set of participants to a pool. However, this is not the object of this paper.

\subsubsection{CP Participants'Age Distribution}

The proposed modified version of the Pearson similarity index, introduced by Equation (2), controls the distribution of the age of the participants in a generic pool. To exemplify, Tables 8 and 9 report the mean value, range and standard deviation of the age of the car poolers within each generated clusters of users adopting vehicles of capacity equal to respectively 5 and 3 . The mean value of the range passes from 18.68 years to 8.62 years $(\varepsilon=$ $0.6)$ and 7.62 years $(\varepsilon=0.75)$ when the capacity is 5 , and from 12.82 to $8.09(\varepsilon=0.6)$ and $7.71(\varepsilon=0.75)$ when the capacity is reduced to 3 . The same considerations can be drawn analyzing the age standard deviation values quantified for each generated pool.

These results demonstrate that it is possible to develop problem oriented similarity indices able to support different levels of homogeneity among the participants of 
Table 7. Site “A. Moro, Bologna”. Extra daily load and weekly saving in terms of time and distance. Different vehicles capacity, SIM_1 \& SLINK rule.

\begin{tabular}{|c|c|c|c|c|c|}
\hline vehicle capacity & Similarity threshold & $\begin{array}{l}D 1 \text { : Average std. extra } \\
\text { daily load on distance }\end{array}$ & $\begin{array}{l}\text { D2: Average std. weekly } \\
\text { saving distance }\end{array}$ & $\begin{array}{l}\text { T1: Average std. extra } \\
\text { daily load on time }\end{array}$ & $\begin{array}{l}\text { T2: Average std. } \\
\text { weekly saving time }\end{array}$ \\
\hline & Standard & 7.04 & 1.51 & 5.19 & 1.12 \\
\hline \multirow[t]{3}{*}{5} & Threshold 0.8 & 6.90 & 1.48 & 4.82 & 1.05 \\
\hline & Threshold 0.9 & 6.28 & 1.51 & 4.46 & 1.04 \\
\hline & Standard & 4.09 & 1.40 & 3.25 & 1.13 \\
\hline \multirow[t]{2}{*}{3} & Threshold 0.8 & 3.20 & 1.12 & 2.68 & 0.95 \\
\hline & Threshold 0.9 & 3.23 & 1.13 & 2.69 & 0.95 \\
\hline
\end{tabular}

Table 8. Distribution of the participants' age for different $\varepsilon$. Vehicle capacity $=5$. SIM_1 \& SLINK rule.

\begin{tabular}{|c|c|c|c|c|c|c|c|c|c|}
\hline \multirow{3}{*}{$\begin{array}{c}\text { Similarity Index } \\
\text { Pool }\end{array}$} & \multicolumn{9}{|c|}{ Vehicle capacity $=5$} \\
\hline & \multicolumn{3}{|c|}{ Pearson } & \multicolumn{3}{|c|}{ Pearson_age $(\varepsilon=0.6)$} & \multicolumn{3}{|c|}{ Pearson_age $(\varepsilon=0.75)$} \\
\hline & Mean & Range & StdDev & Mean & Range & StdDev & Mean & Range & StdDev \\
\hline 1 & 40 & 15 & 5.55 & 51.4 & 1 & 0.49 & 51.4 & 1 & 0.49 \\
\hline 2 & 46.2 & 25 & 9.24 & 45.2 & 1 & 0.4 & 45.2 & 1 & 0.4 \\
\hline 3 & 45.2 & 25 & 9.3 & 39.2 & 2 & 0.75 & 39.2 & 2 & 0.75 \\
\hline 4 & 36.4 & 26 & 9.18 & 43 & 2 & 0.89 & 43 & 2 & 0.89 \\
\hline 5 & 46.8 & 22 & 8.16 & 60.6 & 2 & 0.8 & 60.6 & 2 & 0.8 \\
\hline 6 & 49.4 & 12 & 5.43 & 34 & 0 & 0 & 34 & 0 & 0 \\
\hline 7 & 45.8 & 28 & 10.7 & 42.8 & 3 & 1.47 & 39.2 & 21 & 8.18 \\
\hline 8 & 47.6 & 20 & 6.97 & 42.4 & 5 & 1.85 & 41.4 & 1 & 0.49 \\
\hline 9 & 46 & 25 & 8.79 & 46 & 12 & 4.56 & 44.2 & 3 & 1.17 \\
\hline 10 & 38.6 & 8 & 3.77 & 55.2 & 4 & 1.6 & 55.6 & 3 & 1.2 \\
\hline 11 & 42.8 & 16 & 5.49 & 48.6 & 8 & 2.73 & 49.2 & 8 & 3.25 \\
\hline 12 & 43.2 & 24 & 7.76 & 44.2 & 29 & 10.68 & 49.6 & 4 & 1.36 \\
\hline 13 & 43 & 16 & 7.14 & 32.4 & 6 & 2.94 & 32.4 & 6 & 2.94 \\
\hline 14 & 51.25 & 16 & 6.42 & 45.6 & 15 & 6.89 & 45.6 & 15 & 6.89 \\
\hline 15 & 48 & 20 & 7.48 & 45 & 19 & 6.16 & 45 & 19 & 6.16 \\
\hline 16 & 44.75 & 15 & 6.14 & 46.25 & 25 & 9.71 & 46.25 & 25 & 9.71 \\
\hline 17 & 54.5 & 15 & 5.68 & 32.25 & 3 & 1.09 & 32.25 & 3 & 1.09 \\
\hline 18 & 43.5 & 16 & 5.89 & 51.75 & 8 & 3.42 & 51.75 & 8 & 3.42 \\
\hline 19 & 46.75 & 21 & 7.79 & 46 & 12 & 4.69 & 46 & 12 & 4.69 \\
\hline 20 & 46.75 & 17 & 8.26 & 42.5 & 19 & 7.83 & 42.5 & 19 & 7.83 \\
\hline 21 & 48 & 9 & 3.74 & 57.33 & 5 & 2.05 & 57.33 & 5 & 2.05 \\
\hline 22 & 42.33 & 20 & 8.81 & & & & & & \\
\hline Mean & 45.31 & 18.68 & 7.17 & 45.32 & 8.62 & 3.38 & 45.32 & 7.62 & 3.04 \\
\hline
\end{tabular}


Table 9. Distribution of the participants' age for different $\varepsilon$. Vehicle capacity $=3$. SIM_1 \& SLINK rule.

\begin{tabular}{|c|c|c|c|c|c|c|c|c|c|}
\hline \multirow{3}{*}{$\frac{\text { Similarity Index }}{\text { Pool }}$} & \multicolumn{9}{|c|}{ Vehicle Capacity $=3$} \\
\hline & \multicolumn{3}{|c|}{ Pearson } & \multicolumn{3}{|c|}{ Pearson_age $(\varepsilon=0.6)$} & \multicolumn{3}{|c|}{ Pearson_age $(\varepsilon=0.75)$} \\
\hline & Mean & Range & StdDev & Mean & Range & StdDev & Mean & Range & StdDev \\
\hline 1 & 45.33 & 26 & 10.87 & 51 & 0 & 0 & 51 & 0 & 0 \\
\hline 2 & 40 & 21 & 8.6 & 41 & 0 & 0 & 41 & 0 & 0 \\
\hline 3 & 50.67 & 3 & 1.25 & 45 & 0 & 0 & 45 & 0 & 0 \\
\hline 4 & 41.67 & 6 & 2.62 & 52.33 & 1 & 0.47 & 52.33 & 1 & 0.47 \\
\hline 5 & 50.33 & 18 & 8.06 & 39.33 & 1 & 0.47 & 39.33 & 1 & 0.47 \\
\hline 6 & 34.67 & 28 & 11.9 & 43.67 & 1 & 0.47 & 43.67 & 1 & 0.47 \\
\hline 7 & 44.33 & 2 & 0.94 & 58.33 & 4 & 1.89 & 58.33 & 4 & 1.89 \\
\hline 8 & 37.33 & 12 & 4.99 & 51.33 & 26 & 12.26 & 51.33 & 26 & 12.26 \\
\hline 9 & 47.33 & 22 & 9.29 & 37.67 & 11 & 5.19 & 37.67 & 11 & 5.19 \\
\hline 10 & 37.33 & 18 & 7.72 & 36.33 & 7 & 3.3 & 36.33 & 7 & 3.3 \\
\hline 11 & 41.33 & 20 & 8.22 & 44 & 0 & 0 & 44 & 0 & 0 \\
\hline 12 & 55.67 & 2 & 0.94 & 46.33 & 13 & 6.13 & 46.33 & 13 & 6.13 \\
\hline 13 & 40.67 & 20 & 9.43 & 36.33 & 20 & 9.43 & 42 & 3 & 1.41 \\
\hline 14 & 41.33 & 1 & 0.47 & 51 & 17 & 7.79 & 56 & 2 & 0.82 \\
\hline 15 & 42 & 4 & 1.63 & 38.33 & 25 & 11.79 & 35.67 & 17 & 8.01 \\
\hline 16 & 43 & 13 & 5.35 & 41.33 & 9 & 4.03 & 40.33 & 6 & 2.62 \\
\hline 17 & 52.67 & 14 & 5.73 & 51 & 11 & 4.97 & 49 & 17 & 7.79 \\
\hline 18 & 43.67 & 7 & 3.09 & 43 & 8 & 3.56 & 43.67 & 6 & 2.62 \\
\hline 19 & 40.33 & 9 & 3.68 & 45.67 & 9 & 4.03 & 47.67 & 3 & 1.25 \\
\hline 20 & 46 & 23 & 9.42 & 39.33 & 10 & 4.71 & 39.67 & 11 & 5.19 \\
\hline 21 & 42 & 9 & 3.74 & 43.67 & 5 & 2.36 & 46.33 & 13 & 6.13 \\
\hline 22 & 54 & 14 & 5.89 & 52 & 6 & 2.45 & 45 & 18 & 7.87 \\
\hline 23 & 48.33 & 10 & 4.71 & 38 & 6 & 2.83 & 42.33 & 7 & 3.3 \\
\hline 24 & 52.67 & 17 & 6.94 & 44.67 & 4 & 1.7 & 49.67 & 19 & 8.73 \\
\hline 25 & 45 & 29 & 11.86 & 54 & 14 & 5.89 & 43.33 & 22 & 9.57 \\
\hline 26 & 45 & 15 & 7.07 & 31.33 & 2 & 0.94 & 33.33 & 4 & 1.89 \\
\hline 27 & 50.33 & 11 & 4.5 & 47 & 19 & 8.04 & 52.67 & 5 & 2.05 \\
\hline 28 & 47 & 12 & 6 & 49.67 & 5 & 2.36 & 52 & 12 & 5.66 \\
\hline 29 & 52.5 & 5 & 2.5 & 45 & 23 & 10.61 & 32.67 & 15 & 6.85 \\
\hline 30 & 51.5 & 7 & 3.5 & 47.67 & 5 & 2.05 & 47.67 & 5 & 2.05 \\
\hline 31 & 38.5 & 1 & 0.5 & 52.5 & 5 & 2.5 & 52.5 & 5 & 2.5 \\
\hline 32 & 50 & 6 & 3 & 57.5 & 5 & 2.5 & 57.5 & 5 & 2.5 \\
\hline 33 & 38.5 & 17 & 8.5 & 54 & 2 & 1 & 54 & 2 & 1 \\
\hline 34 & 41 & 14 & 7 & 30.5 & 1 & 0.5 & 30.5 & 1 & 0.5 \\
\hline Mean & 45.06 & 12.82 & 5.59 & 45.29 & 8.09 & 3.71 & 45.29 & 7.71 & 3.54 \\
\hline
\end{tabular}


the generated car pools: the homogeneity can be evaluated on different attributes and combination of attributes defined and measured for each car pooler, e.g. age, sex, hobbies, education, occupational tasks and job.

\subsection{Case Study Summary Results}

Table 10 summarizes the results obtained by the application of the proposed CP approach and settings to the whole set of potential participants in the case study object of the analysis. All results refer to the application of the quickest routing strategy, the clustering based on time, the SLINK heuristic algorithm but without any modification, e.g. threshold limit of similarity, and without the introduction of age-based controls. Savings of more than $20 \%$ in the number of kilometres travelled and time spent travelling as drivers, demonstrate the efficacy of the proposed models and agglomerative approach. In particular, larger is the number of potential participants and higher is the estimated percentage saving, e.g. about $27.6 \%$ (saving distance) and $24.9 \%$ (saving time) when the number of participants is over 300 .

Figure 8 presents a graphical illustration of the relationship between the number of participants and the corresponding saving distance in the case study object of this paper.

The whole amount of kilometres saved in a week is $45,826 \mathrm{~km} /$ week, i.e. about 2 millions of kilometres in a year assuming 44 working weeks in a year. Given an average values of car $\mathrm{CO}_{2}$ emission rating of $150 \mathrm{~g} / \mathrm{km}$ (grams of carbon dioxide per kilometre driven) corresponding to an average emissions of new cars, the number of carbon dioxide tons saved in a year is about 244 corresponding to at least one thousand of trees to offset these emission per year. We know that the used cars are not new and the previously quantified tons of emissions and number of trees are underestimated.

Table 10. Performance evaluation for all working site locations. Case study \& SLINK rule.

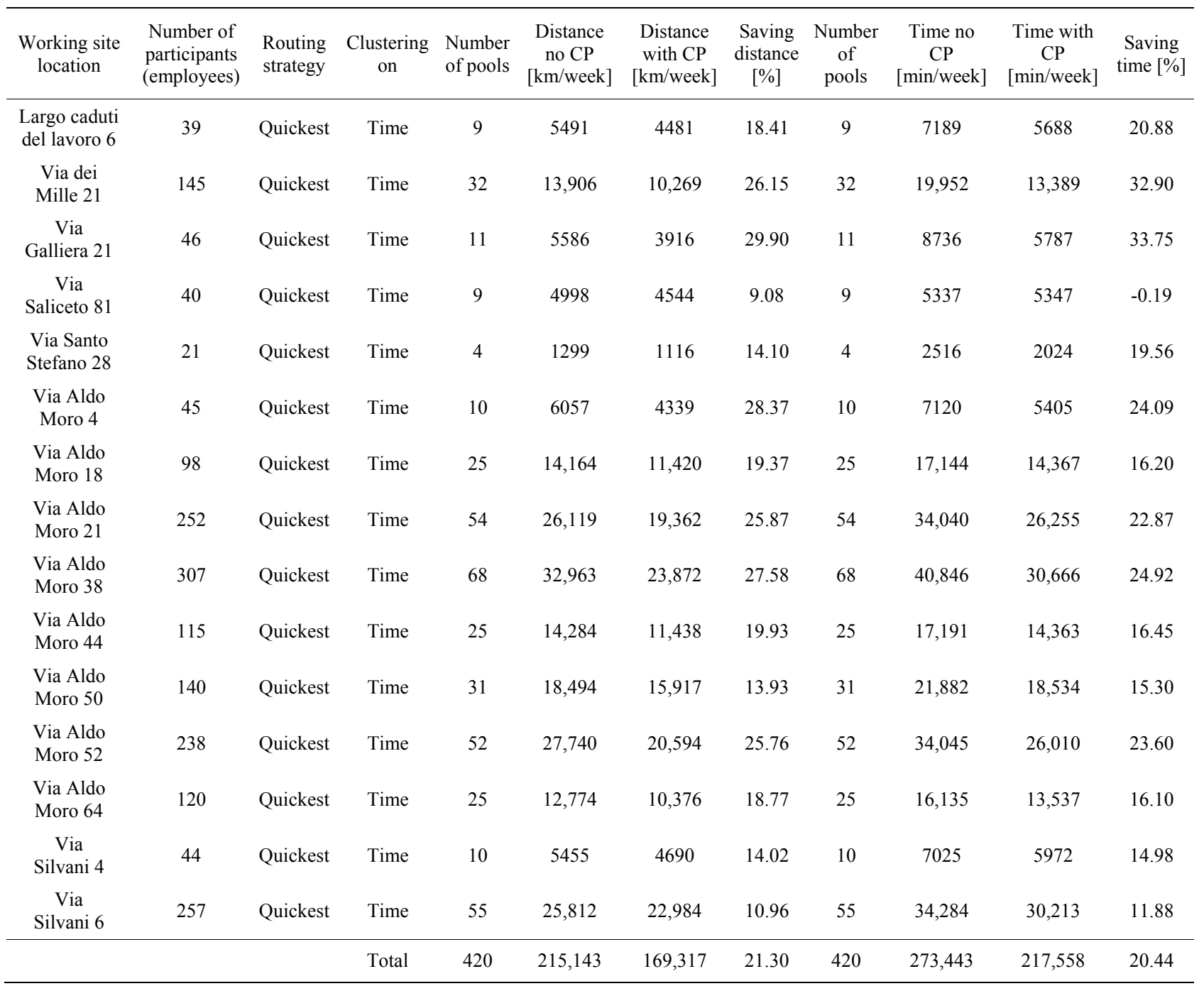




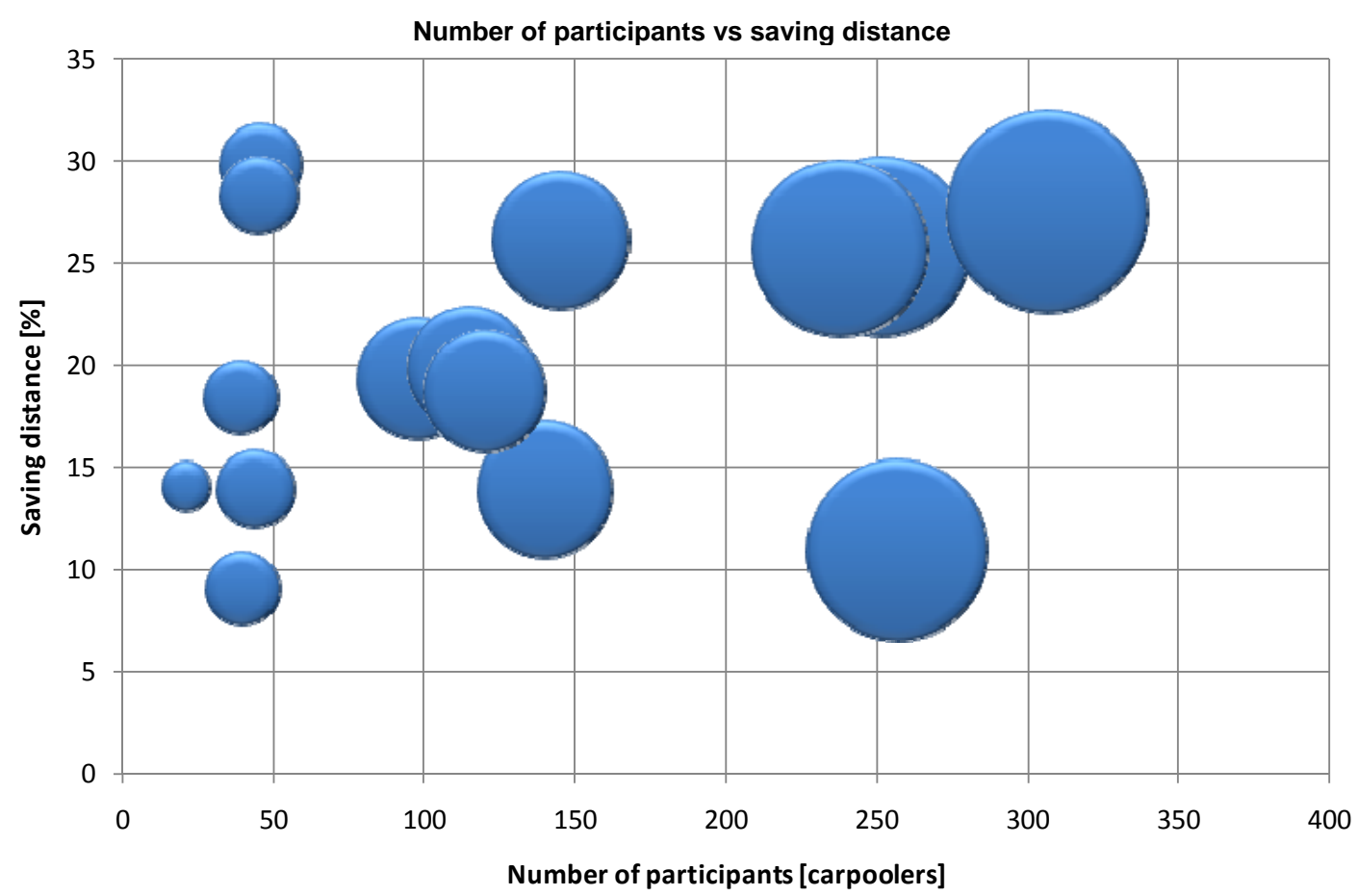

Figure 8. Number of participants vs saving distance. Case study.

This is a case study and not a way to find general results.

\section{Conclusions and Further Research}

In mobility management, there are several targets established by the institutions, such as the EC, and a lot of strategies and rules, but a few models and tools available to support the decisions making process of managers.

This paper presents an original approach to the CP problem. It is based on the integration of similarity based clustering analysis and vehicle routing optimization. An original decision supports system (DSS) for the mobility manager is also developed and applied to best matching the participants to a $\mathrm{CP}$ program and best define daily vehicle routes. A significant case study demonstrates the effectiveness of the proposed approach and the efficiency of the developed automatic tool.

Further research is expected on:

- Development of programs of education to sustainability, responsibility and health;

- The development of surveys and questionnaires to collect data on uses, preferences and behaviours of EU and not EU workers. It is very important to understand and control the differences among different countries and to identify the levels of correlation between them and other community characteristics, such as the level of education, the status of infrastructures, the most used and developed transportation modes, the most developed industry sectors, etc.;
- The development of models and tools to quantitatively measure the effects of CP and other transportation strategies and policies on the employee, the community of people and the environment. It is very important to define the best combination of cost based key performance indices (KPI) to estimate and measure them;

- The development of effective tools and supporting decision systems to encourage CP. They have to be based on economic and not economic incentives and disincentives to the use of own cars;

- The development of automatic tools to efficiently and effectively support the grouping process and the routing activities for other commuting strategies and rules;

- The development of tools to plan the effects of different combination of transportation strategies and policies to move people and materials. A what-if analysis can support the managers, e.g. mobility managers, logistics managers in the industry and service sectors, and urban policy managers, to identify the best mix of solutions. To this purpose the cost based approach proposed and applied in this paper can represent a first reference;

- Conduction of what-if analyses capable of estimating the social, environmental and economic performance and benefits associated to new transport strategies and issues;

- Development and diffusion of standards and specs to effectively support the urban sustainability due to the 
management of transportation issues.

\section{REFERENCES}

[1] Eurostat European Commission, "Energy, Transport and Environment Indicators,” 2009.

[2] R. Baldacci, V. Maniezzo and A. Mingozzi, "An Exact Method for the Car Pooling Problem Based on Lagrangian Column Generation," Operations Research, Vol. 53, No. 3, 2004, pp. 422-439. doi:10.1287/opre.1030.0106

[3] World Business Council for Sustainable Development, "The Sustainable Mobility Project," Full Report, 1 June 2004.

[4] J. Sousanis, "World Vehicle Population Tops 1 Billion Units," Ward Auto World, 2011.

[5] S. Yan and C. Y. Chen, "An Optimization Model and a Solution Algorithm for the Many-to-Many Car Pooling Problem," Annals of Operations Research, Vol. 191, No. 1, 2011, pp. 37-71. doi:10.1007/s10479-011-0948-6

[6] Y. Guo, G. Goncalves and T. Hsu, "A Clustering Ant Colony Algorithm for the Long-Term Car Pooling Problem," International Conference on Swarm Intelligence, Cergy, 14-15 June 2011, pp. 1-10.

[7] A. Garling and A. Johansson, "Household Choices of Car-Use Reduction Measures," Transportation Research, Part A: Policy and Practice, Vol. 34, No. 5, 2000, pp. 309-20. doi:10.1016/S0965-8564(99)00039-7

[8] R. Manzini and F. Bindi, "Strategic Design and Operational Management Optimization of a Multi Stage Physical Distribution System," Transportation Research Part E: Logistics and Transportation Review, Vol. 45, No. 6, 2009, pp. 915-936. doi:10.1016/j.tre.2009.04.011

[9] R. Manzini, M. Bortolini, M. Gamberi and M. Montecchi, "A Supporting Decision Tool for the Integrated Planning of a Logistic Network," In: S. Renko, Ed., Supply Chain Management-New Perspectives, InTech, Rijeka, 2011. $\mathrm{http} / /$ www.intechopen.com/books/supply-chain-manage ment-new-perspectives/a-supporting-decision-tool-for-the -integrated-planning-of-a-logistic-network

[10] E. Ferrari, R. Manzini, A. Pareschi, A. Persona and A. Regattieri, "The Car Pooling Problem: Heuristic Algorithms Based on Savings Functions," Journal of Advanced Transportation, Vol. 37, No. 3, 2003, pp. 243-272. doi:10.1002/atr.5670370302

[11] EEA Report, "Climate for a Transport Change. TERM 2007: Indicators Tracking Transport and Environment in the European Union," European Environment Agency, 2008.
[12] Eurostat European Commission, "Panorama of Transport," 2007.

http://www.google.it/url?sa=t\&rct=j\&q=\&esrc=s\&source $=$ web\&cd $=1 \&$ ved $=0$ CDEQFjAA\&url $=\mathrm{http} \% 3 \mathrm{~A} \% 2 \mathrm{~F} \% 2 \mathrm{~F}$ epp.eurostat.ec.europa.eu $\% 2$ Fcache $\% 2$ FITY_OFFPUB $\%$ 2FKS-DA-07-001\%2FEN\%2FKS-DA-07-001-EN.PDF\& ei=JySET8izEun04QTMnoXbBw\&usg=AFQjCNHQQ_q 5-r3k-24ao_E_cg8nJ1V_Zg\&sig2=22d81SfbuQFSKVAY TdWSyA

[13] EEA Report, "Transport and Environment: On the Way to a New Common Transport Policy," European Environment Agency, 2007.

[14] Eurobarometer, "Attitudes on Issues Related to EU Transport Policy: Analytical Report, the Gallup Organization," European Commission, 2007.

http://www.google.it/url?sa=t\&rct=j\&q=\&esrc=s\&source $=$ web\&cd $=1 \&$ ved $=0$ CDIQFjAA\&url $=$ http $\% 3 \mathrm{~A} \% 2 \mathrm{~F} \% 2 \mathrm{Fe}$ c.europa.eu $\% 2 \mathrm{Fpublic}$ opinion $\% 2 \mathrm{Fflash} \% 2 \mathrm{Ffl} 206 \mathrm{~b}$ en. pdf\&ei=qySET6PBOqTN4QTY_6HIBw\&usg=AFQjCN FX4i8KPfrvf5O5JD2Ke2iUWi-xUg\&sig2=KnHMULWy 72Xh4jvvMHslow

[15] UKERC, "Quick Hits: Car Clubs," Environmental Change Institute, Oxford, 2007.

[16] R. Manzini, F. Bindi and A. Pareschi, "The Threshold Value of Group Similarity in the Formation of Cellular Manufacturing System," International Journal of Production Research, Vol. 48, No. 10, 2009, pp. 3029-3060. doi:10.1080/00207540802644860

[17] A. Villa, I. Cassarino and D. Antonelli, "Extending Group Technology to the Identification and the Analysis of Enterprise Networks," International Journal of Production Research, Vol. 45, No. 17, 2007, pp. 3881-3892.

[18] R. W. Calvo, F. de Luigi, P. Haastrup and V. Maniezzo, "A Distributed Geographic Information System for the Daily Car Pooling Problem," Computers \& Operations Research, Vol. 31, No. 13, 2004, pp. 2263-2278. doi:10.1016/S0305-0548(03)00186-2

[19] M. Naor, "On Fairness in the Carpool Problem," Journal of Algorithms, Vol. 55, No. 1, 2005, pp. 93-98. doi:10.1016/j.jalgor.2004.05.001

[20] M. A. Vargas, J. Sefair, J. L. Walteros, A. L. Medaglia and L. Rivera, "Car Pooling Optimization: A Case Study in Strasbourg (France)," Proceedings of the 2008 IEEE Systems and Information Engineering Design Symposium, Vargas, 25 April 2008, pp. 89-94.

[21] E. W. Dijkstra, "A Note on Two Problems in Connexion with Graphs," Numerische Mathematik, Vol. 1, No. 1, 1959, pp. 269-271. doi:10.1007/BF01386390 